\title{
FU-LV Regimen
}

National Cancer Institute

\section{Source}

National Cancer Institute. FU-LV Regimen. NCI Thesaurus. Code C63388.

A regimen consisting of fluorouracil and leucovorin, used in both the adjuvant and metastatic disease setting, for the treatment of colorectal cancer. This regimen is also combined with radiation for the treatment of gastric and esophageal cancer. 